CENDEKIA, Vol. 11, No. 2, Oktober 2017

p ISSN: 1978 2098; e ISSN: 2407 8557

Http://cendekia.pusatbahasa.or.id; Email: cendekiaoslo@gmail.com Center of Language and Culture Studies, Surakarta, Indonesia

Solikhah, Imroatus. 2017. Silabus EAP Berbasis Learning Outcomes

untuk Mahasiswa IAIN Surakarta. Cendekia (2017), 11(2): 263 278.

\title{
SILABUS EAP BERBASIS LEARNING OUTCOMES UNTUK MAHASISWA IAIN SURAKARTA
}

\section{Imroatus Solikhah \\ IAIN Surakarta Jl. Pendawa, Pucangan, Kartasura \\ Email: ratu.shyma@yahoo.com}

\begin{abstract}
The objectives of this study are: (1) to describe conditions of $M K D U$ Bahasa Inggris at IAIN Surakarta, (2) to formulate needs analysis of Learning Outcomes-Based EAP program at IAIN Surakarta, and (3) to develop a syllabus of Learning Outcomes-Based EAP Program at at IAIN Surakarta. The design of this study is R2D2 (Recursive, Reflective, Design and Development) that used three phases: define, design and develop, and disseminate and assigned 3 language experts, 6 English lecturers, and 20 students as research subjects. This study finds two findings. First, conditions of $M K D U$ Bahasa Inggris program at IAIN Surakarta are not standard. MKDU Bahasa Inggris is general English and syllabus is not available. Second, Learning Outcomes EAP Syllabus should be used to achieve academic literacy and minimum English competency. The core materials include: reading for literal, inferential, and critical; speaking for informal, formal, and academic setting; general word list 1,000 to 2,000, academic vocabulary, basic grammar, and academic grammar.
\end{abstract}

Key-words: EAP, learning outcomes, syllabus.

English for Academic Purposes (EAP) pada saat ini mendapat perhatian amat luas di dunia dan EAP telah menjadi cabang tersendiri dalam English Language Teaching (ELT). Universitas di inner circle countries (negara pengguna bahasa Inggris sebagai bahasa pertama-L1, misalnya Amerika, Inggris) menetapkan kompetensi bahasa Inggris yang sangat tinggi sebagai syarat mengikuti perkuliahan (Wilson, 2009). Negara-negara outer circle, misalnya Singapura, Malaysia, Filipina, Turki, Bangladesh, India sebagai pengguna ESL (English as a Second Language) dan negara expanding circle, misalnya Mesir, Korea, Indonesia, Jepang, Vietnam sebagai pengguna EFL (English as a Foreign Language) menyesuaikan kebijakan program EAP secara luas (Yurekli, 2012; Bojrkman, 2013).

Saat ini EAP telah diterima sebagai paket program terintegrasi dilihat dari tiga aspek. Pertama, program EAP dilaksanakan terintegrasi dengan desain silabus dan buku teks sebagai pedoman pembelajaran dan materi ajar (Hyland, 2006:4). Kedua, program EAP disusun berdasarkan analisis kebutuhan pembelajar dan bertujuan untuk mencapai literasi akademik (Yurekli, 2012; Bojrkman, 2013). Ketiga, EAP bukan program untuk memperoleh penguasaan keterampilan bahasa, tetapi penguatan untuk mencapai literasi akademik.

EAP telah memperoleh kedudukan yang begitu luas di dunia karena pengaruh bahasa Inggris sebagai lingua franca dunia. Australia misalnya, pada 2007 telah membukukan devisa sebesar $\$ 11.7$ atau setara dengan $\mathrm{Rp} 287$ trilyun dari penyelenggaraan EAP. EAP telah menjadi komoditas ekspor terbesar ketiga setelah 
batubara dan tambang besi (Wilson, 2009:15). Di Indonesia, potret potensi EAP telah diteliti oleh Solikhah (2013; 2014). Solikhah (2014) melaporkan peserta EAP di PTN di Jawa Tengah mencapai 40.000-60.000 per tahun. Satu PTN di Jawa Tengah dan DIY memiliki mahasiswa yang wajib menempuh MKDU Bahasa Inggris antara 8.000-10.000 orang per tahun. MKDU Bahasa Inggris ini sebenarnya arketipe EAP dalam bentuk sederhana.

MKDU Bahasa Inggris untuk jurusan non-bahasa Inggris yang dilaksanakan sebagai program wajib di seluruh perguruan tinggi di Indonesia, PTN maupun PTS, sebenarnya ialah program yang sudah jenuh. MKDU Bahasa Inggris ini dilaksanakan sebagai mata kuliah pelengkap sesuai struktur kurikulum perguruan tinggi dan tujuan pembelajarannya ialah English for General Course (EGS). Dalam kondisi demikian, MKDU Bahasa Inggris tidak didukung dengan analisis kebutuhan, silabus yang mantap dan buku teks yang sesuai (Solikhah, 2014:194). Pelaksanaan EAP yang sedikit lebih maju ialah EAP dilaksanakan di UP2B (Unit Pusat Pengembangan Bahasa) di setiap universitas, tetapi pelaksanaannya terbatas pada mengalihkan penyelenggara dari Program Studi ke UP2B. Program pembelajaran dan orientasi program masih kurang lebih sama dengan MKDU Bahasa Inggris. Yang agak membedakan ialah UP2B menyelenggarakan tes kompetensi, misalnya TOEFL untuk mahasiswa walaupun proses pembelajarannya belum sesuai dengan tujuan EAP. Analisis kebutuhan, silabus, dan buku teks ditentukan oleh pengelola UP2B.

MKDU Bahasa Inggris di IAIN Surakarta memiliki karakteristik yang sama dengan MKDU Bahasa Inggris yang dilaksanakan di PTN di Jawa Tengah dan DIY. Pertama, MKDU Bahasa Inggris di IAIN dilaksanakan sebagai mata kuliah wajib yang diselenggarakan dalam bentuk EGS dengan bobot 2-4 sks. Kedua, MKDU Bahasa Inggris dilaksanakan dalam kelas besar antara 40 mahasiswa per kelas. Ketiga, tujuan pembelajaran ialah pembekalan pengetahuan bahasa Inggris dan tidak ada standar capaian, misalnya kompetensi. Keempat, silabus, buku teks dan evaluasi hasil belajar ditetapkan sendiri oleh dosen pengajar berbentuk nilai lulus. Kelima, IAIN juga mengelola UP2B tetapi tujuan pembelajaran, silabus, buku teks dan metodologi pembelajaran belum mengacu pada karakteristik EAP.

MKDU Bahasa Inggris di IAIN Surakarta dalam tahun ajaran 2014/2015 telah dilaksanakan di UP2B dan wajib diikuti oleh setiap mahasiswa. Pada 2014, tercatat ada antara 1.000 mahasiswa yang wajib menempuh program bahasa Inggris melalui UP2B di IAIN. UP2B juga menyiapkan buku teks untuk mahasiswa. Program yang diberi bobot 4 sks ini diselenggarakan pada semester ganjil dan semester genap.

Kajian lebih cermat terhadap buku teks bahasa Inggris yang digunakan di UP2B IAIN Surakarta menunjukkan beberapa hal. Pertama, buku berisi materi grammar sehingga bisa disimpulkan bahwa pembelajaran berbasis Grammar Translation Method. Kedua, tujuan pembelajaran melihat dari isi buku teks tersebut ialah penguasaan language components yaitu grammar. Ketiga, tidak ada analisis kebutuhan yang digunakan untuk menyusun isi dan organisasi buku teks. Keempat, tidak ada silabus yang dikembangkan berdasarkan tujuan dan kebutuhan pembelajar. Atas dasar hal tersebut, penelitian ini memfokuskan pada penyesuaian orientasi pelaksanaan EAP di IAIN yang sesuai. Pembelajaran MKDU Bahasa Inggris yang belum didasarkan pada 
hasil belajar berbasis kompetensi perlu disesuaikan dengan kebutuhan masyarakat sekarang.

Silabus sebagai perangkat dasar utama pelaksanaan program perlu dikembangkan secara cermat melalui analisis kebutuhan. Silabus ialah pemilihan dan pengorganisasian pembelajaran bahasa; silabus merupakan perencanaan mengenai apa yang akan dicapai melalui pengajaran dan proses belajar siswa. Menurut Candlin (1984:47), silabus ialah spesifikasi dan perencanaan mengenai apa yang akan dipelajari, umumnya dituangkan secara tertulis dalam bentuk rumusan tertentu sebagai landasan untuk mengajar bagi guru dan belajar untuk siswa. Silabus juga merupakan petunjuk capaian hasil belajar dan perangkat penilaian yang digunakan. Silabus ialah pernyataan tentang apa yang mau diajarkan, berisi poin-poin tentang metode mengajar dan waktu yang digunakan.

Silabus memiliki unsur penting berupa tujuan, isi dan organisasi dari suatu program pembelajaran yang disebut "course". Course ialah rangkaian pengalaman mengajar dan belajar yang terintegrasi, dengan tujuan utama mengarahkan siswa untuk mencapai pengetahuan tertentu (Hutchinson, 1996:65). Materi ajar dan prosedur pembelajaran harus diuraikan dalam bentuk tujuan umum (aims) dan tujuan pembelajaran (goals).

Dalam pembelajaran berbasis kompetensi, hasil belajar diukur bukan berdasarkan tujuan pembelajaran tetapi learning outcomes (LO). LO menunjukkan apa yang sebenarnya dipelajari oleh pembelajar. LO terdiri dari tiga level: outcomes umum, outcomes program, dan outcomes mata kuliah (Palm Beach State College, 2013:2). LO ialah skill dan pengetahuan yang harus dikuasai pembelajar setelah program selesai. Jadi, LO merupakan pernyataan apa yang harus dicapai pembelajar setelah mengikuti program pembelajaran (Queen Mary University of London, 2013:6).

LO yang baik harus terkait dengan tujuan porgram, merujuk pada kriteria eksternal, dan jelas untuk staf, pembelajar, dan penguji eksternal (Queen Mary University of London, 2013:7). LO harus berpusat pada pembelajar, spesifik, dan bisa diukur atau diamati. LO terkait dengan aim/goal dan objectives. Salah satu teknik menyusun LO ialah menggunakan rumus A-B-C-D (Palm Beach State College, 2013:89), Audience, Behavior, Condition, Degree.

Contoh:

\begin{tabular}{|l|l|}
\hline The students & Audience \\
\hline $\begin{array}{l}\text { will apply appropriate techniques for addressing a policy decision } \\
\text { problem }\end{array}$ & Bahavior \\
\hline when givenone, & Condiiton \\
\hline $90 \%$ of the time & Degree \\
\hline
\end{tabular}

Pernyataan LO bisa dielaborasi ke dalam tiga komponen: (1) kata kerja operasional (action words) yang mengidentifikasi kinerja yang harus ditunjukkan, (2) pernyataan belajar (learning statement) yang menunjukkan secara spesifik belajar apa yang harus ditunjukkan dalam kinerja, dan (3) pernyataan umum mengenai kriteria atau standar kinerja sebagai ukuran. Objectives menjabarkan LO dan merupakan tahapan 
bagaimana langkah-langkah mencapai kompetensi yang harus dilakukan pembelajar (The Learning Management Corporation, 2013:1). Istilah aim dan goal memiliki makna yang sama, yaitu tujuan umum pembelajaran. Goal banyak digunakan di Amerika sedangkan aim digunakan di Eropa dan Asia. Istilah objectives memiliki makna tujuan khusus dan merupakan penjabaran dari goal/aim.

\section{Contoh aim, objective dan learning outcomes}

\begin{tabular}{|c|c|c|}
\hline Aims & Objective & Learning outcome \\
\hline $\begin{array}{l}\text { Reading-To develop } \\
\text { reading skill in three } \\
\text { levels of } \\
\text { comprehension }\end{array}$ & $\begin{array}{l}\text { To demonstrate the skills } \\
\text { in literal, inferential, and } \\
\text { critical comprehension on } \\
\text { the passage of } 3,000 \text { word } \\
\text { and academic vocabulary }\end{array}$ & $\begin{array}{l}\text { Students should be able to } \\
\text { demonstrate reading skills of } \\
\text { a text } 3.000 \text { words and } \\
\text { academic vocabulary. }\end{array}$ \\
\hline
\end{tabular}

Contoh berikut menunjukkan bagaimana aim/goal dijabarkan ke dalam learning objectives (Arreola \& Lawrence, 1998:4). Satu aim atau goal bisa dikembangkan ke dalam beberapa objectives. Goal menujukkan tujuan umum pembelajaran dan objectives menujukkan tujuan khusus pembelajaran. Goal menjelaskan kompetensi mata kuliah yang dipelajari, sedangkan objectives menunjukkan komponen kompetensi yang harus dikuasai pembelajar untuk mencapai kompetensi dalam goal.

\begin{tabular}{|l|l|}
\hline Aim/goal & $\begin{array}{l}\text { The aim of the Learning Assessment course is to enable the } \\
\text { students to make reliable and accurate assessment of learning. }\end{array}$ \\
\hline Objective 1 & $\begin{array}{l}\text { Given a learning objective the student will be able to develop } \\
\text { an approppriate multiple-choice question to measure students } \\
\text { achievement of the objective. }\end{array}$ \\
\hline Objective 2 & $\begin{array}{l}\text { Given a printout from an item analysis of a multiple-choice } \\
\text { exam the student will be able to state accuracy of the test } \\
\text { scores. }\end{array}$ \\
\hline Objective 3 & $\begin{array}{l}\text { Given the discrimination and difficulty indices of an item the } \\
\text { student will be able to determine if the item contributes to the } \\
\text { reliability of the exam }\end{array}$ \\
\hline
\end{tabular}

Untuk merumuskan tujuan program secara benar, diperlukan analisis kebutuhan. Analisis kebutuhan merupakan identifikasi tujuan pembelajaran sebelum program dilaksanakan. Richards (2013:22) menjelaskan identifikasi hasil belajar atau objectives sering tergantung pada analisis sistematis kebutuhan komunikatif pembelajar. Needs analysis merupakan bagian dari proses menentukan aims dan objectives. Konsep needs analysis diperkenalkan oleh Munby (1978:21) dan diadopsi untuk menyusun analisis kebutuhan EAP. Munby mengemukakan faktor yang harus dipenuhi dalam menyusun kebutuhan belajar, yaitu: latar belakang siswa, tujuan belajar bahasa, setting, peranan interaksi, bahasa untuk komunikasi, modus komunikasi, dimensi ujaran, dan alat untuk interaksi. Richards (2013:32-33) menegaskan analisis kebutuhan menentukan keberhasilan pelaksanaan EAP. Analisis kebutuhan harus dilaksanakan lebih dulu 
sebelum bahan ajar. Analisis kebutuhan yang utama dalam EAP ialah: (1) tujuan pembelajar, (2) riwayat pendidikan pembelajar, (3) lama waktu belajar, (4) cara belajar secara individu, dan (5) situasi sosial.

Sesuai dengan latar belakang masalah di atas, terlebih dulu penelitian mengkaji bagaimana tingkat kebutuhan mahasiswa dalam belajar bahasa Inggris. Selanjutnya, penelitian merumuskan desain silabus yang sesuai dengan tujuan pembelajar. Tahap awal memberi keuntungan bagaimana MKDU Bahasa Inggris disesuaikan dengan kebutuhan belajar bahasa Inggris. Potensi mahasiswa dengan rata-rata 1.000 orang setahun, merupakan potensi besar yang harus dikelola dengan baik. Untuk itu, program MKDU Bahasa Inggris perlu direvitalisasi dengan mengarahkan pada program EAP agar potensinya berkembang maksimal baik secara finansial maupun pemenuhan kebutuhan akademik dari aspek penguatan bahasa. Penelitian ini bertujuan untuk: (1) Mendeskripsikan kondisi pembelajaran MKDU Bahasa Inggris untuk mahasiswa jurusan non-bahasa Inggris di IAIN Surakarta, (2) Mengkaji tingkat kebutuhan EAP Berbasis Learning Outcomes untuk mahasiswa jurusan non-bahasa Inggris di IAIN Surakarta, dan (3) Merumuskan bentuk baku desain silabus EAP Berbasis Learning Outcomes untuk mahasiswa jurusan non-bahasa Inggris di IAIN Surakarta.

\section{METODE}

Desain penelitian ini adalah Recursive Reflective Design and Development (R2D2) dari Willis (1995). Model ini bersifat recursive, artinya berulang-ulang dan juga perenungan (reflective). Aktifitas Define meliputi: analisis awal akhir, analisis pembelajar, analisis tugas, analisis konsep, dan menspesifikasi tujuan pembelajaran. Aktifitas Design dan Develop meliputi: pemilihan media dan format, pemilihan lingkungan pengembangan, desain produk dan pengembangan, dan strategi evaluasi. Aktifitas Disseminate meliputi: pemaketan akhir, pengiklanan, pelatihan, workshop.

Prosedur penelitian R2D2 ini terdiri dari tiga tahap, yakni (1) pendefinisian, (2) perencanaan dan pengembangan, dan (3) penyebarluasan. Langkah-langkah yang dilakukan meliputi: pembentukan tim kolaboratif, studi pendahuluan (tahap pemfokusan), mendesain dan mengembangkan produk, mengadakan uji coba produk, merevisi produk, dan diseminasi produk. Pembentukan tim kolaboratif terdiri atas: ahli, dosen, dan mahasiswa. Masalah-masalah yang muncul dalam proses pengembangan dipecahkan melalui konsultasi dan diskusi dengan tim. Studi pendahuluan dilakukan dengan teknik kaji dokumen, observasi, angket dan wawancara. Data yang terkumpul melalui studi pendahuluan ini akan digunakan sebagai pijakan dalam pengembangan produk penelitian dan analisis kebutuhan mahasiswa dalam EAP Berbasis Learning Outcomes.

Subjek uji produk penelitian ini meliputi tiga kelompok. Pertama, kelompok ahli yang terdiri dari tiga orang ahli metodologi pembelajaran bahasa Inggris. Kedua, kelompok dosen MKDU Bahasa Inggris di IAIN sebanyak enam orang. Ketiga, kelompok mahasiswa peserta MKDU Bahasa Inggris dan peserta pelatihan di UP2B IAIN, masing-masing 10 orang.

Pengumpulan data dilakukan dengan pemberian angket dan lembar saran kepada subjek uji produk. Angket untuk ahli pembelajaran Bahasa Inngris dan dosen berkaitan dengan ketepatan konsep materi ajar, organisasi materi pokok, SK-KD, dan model 
silabus. Angket untuk mahasiswa berkaitan dengan kesesuaian tujuan pembelajaran, isi materi, dan organisasi materi dalam silabus. Data penelitian ini adalah data validasi hasil pengembangan buku ajar yang diperoleh ketika uji produk. Data angka dari angket dianalisis dengan teknik persentase, sedang data verbal yang berupa kritik, saran, dan komentar yang ditulis berkas silabus.

\section{HASIL PENGEMBANGAN \\ Tahap Pendefinisian}

\section{Kondisi Pembelajaran MKDU Bahasa Inggris di IAIN Surakarta}

Kondisi pembelajaran MKDU Bahasa Inggris di IAIN Surakarta dianalisis menggunakan adaptasi kerangka pikir pengembangan kurikulum. Ada tiga hal terkait pelaksanaan pembelajaran MKDU Bahasa Inggris di IAIN Surakarta. Pertama, MKDU Bahasa Inggris di IAIN Surakarta berbobot 2-4 sks dan wajib ditempuh setiap mahasiswa. Kelas diisi antara 40 mahasiswa. Kedua, MKDU Bahasa Inggris diserahkan pembelajarannya kepada dosen pengajar dan materi yang diajarkan juga ditentukan sendiri oleh dosen pengajar. Ketiga, tidak terdapat kurikulum atau silabus baku yang bisa digunakan untuk rujukan. Proses pembelajaran juga belum tertata dengan baik karena aspek manajemen pembelajaran dan penghargaan terhadap dosen belum jelas.

Kondisi khusus MKDU Bahasa Inggris di IAIN Surakarta ialah: (1) Tujuan umum MKDU Bahasa Inggris ialah memberi pengetahuan bahasa Inggris dan mencapai skor TOEFL 400. Tujuan ini tidak sejalan dengan silabus dan bahan ajar yang digunakan dosen selama ini. Dosen menggunakan bahan ajar buatan sendiri dan materi yang diajarkan tidak difokuskan secara sistematis bagaimana skor TOEFL bisa ditingkatkan. (2) Isi bahan ajar diarahkan pada penguasaan grammar dan membaca pemahaman. Jika dicermati secara seksama, isi materi MKDU ini ialah general English dan tidak mengarahkan hasil belajar pada kompetensi tertentu. (3) Pendekatan mengajar MKDU Bahasa Inggris ialah grammar translation methods, karena interaksi lebih banyak menggunakan bahasa Indonesia, materi ajar lebih difokuskan pada grammar dan menjawab pertanyaan membaca.

\section{Analisis Kebutuhan}

Analisis kebutuhan merupakan identifikasi tujuan pembelajaran sebelum program dilaksanakan. Needs analysis merupakan bagian dari proses menentukan aims dan objectives. Hasil wawancara dan jawaban angket terhadap mahasiswa, dosen dan pengelola MKDU Bahasa Inggris di IAIN Surakarta menggambarkan kebutuhan berikut ini: (1) Tujuan pembelajaran: menguasai bahasa Inggris dan meningkatkan skor TOEFL, (2) Menguasai kosa kata, (3) Menguasai grammar, (4) Berbicara bahasa Inggris tahap awal untuk komunikasi lisan, (5) Membaca teks bahasa Inggris, (6) Menyimak, dan (7) Menulis pesan pendek.

\section{Kerangka Silabus EAP Berbasis Learning Outcomes}

Bagian ini menguraikan mengenai kerangka silabus yang dikembangkan berdasarkan hasil analisis kebutuhan. Nama silabus yang dimaksud ialah silabus berbasis learning outcomes. Kerangka silabus mengadaptasi model silabus EAP 
berbasis kompetensi dari Solikhah (2014) dan Solikhah (2014a dan 2014b). Silabus memiliki kerangka isi sebagai berikut:

1. Learning outcomes: By the end of this course, students will be able to demonstrate English competenecies in reading and speaking with appropriate vocabulary and grammar.

2. Learning objectives: to demonstrate 1,000 to 2,000 general word list in reading and speaking; to apply academic vocabulary in reading and speaking; to demonstrate reading skills on literal, inferential and critical comprehension; to demonstrate speaking skills for daily communication.

3. Core materials: (1) Reading for literal, inferential and critical comprehension, (2) general word list at 1,000 to 2,000 words, (3) academic vocabulary, (4) basic grammar and academic grammar, and (5) basic speaking for daily communication, presentation for formal setting and interactions for various instant topics.

Materi inti dalam kerangka isi silabus di atas, terdiri dari membaca, berbicara, kosa kata dan grammar. Materi utama membaca digunakan sebagai dasar pembelajaran untuk mengembangkan skill lainnya, yaitu kosa kata, grammar dan berbicara. Di sini membaca dibagi ke dalam dua level pemahaman, yaitu membaca literal dan membaca inferensial. Membaca kritis diajarkan pada semester berikutnya. Membaca literal meliputi: jenis pemahaman literal, membaca untuk menemukan main ideas, membaca untuk skimming dan scanning, dan mengembangkan kosa kata berdasarkan konteks. Membaca inferential terdiri dari: definisi dan contoh pemahaman inferensial, membuat inferensi, dan menebak makna dengan merujuk pada teks.

Selanjutnya, materi inti kosa kata diambil dari General Word List (GWL) 1.000 dan 2.000 yang dikembangkan oleh West (1950). GWL merupakan daftar kosa kata yang paling sering digunakan (high frequency) dalam kehidupan sehari-hari. GWL dianggap merupakan standar minimal penguasaan bahasa Inggris pada tingkat awal. Bersamaan dengan penguasaan GWL, disajikan juga basic grammar. Topik yang dibahas di antaranya: agreement, to be, tenses, passive voice, plural, gerund, dan modal auxiliaries. Grammar dan kosa kata ini merupakan kompetensi minimal yang harus dikuasai pembelajar sebelum mengembangkan keterampilan berbahasa Inggris membaca, berbicara atau menulis. Adapun kosa kata akademik merujuk pada daftar 300 kata yang dikeluarkan oleh Ohio State University (2013). Kosa kata akademik memiliki bobot lebih tinggi dibanding GWL karena berisi kosa kata yang biasa digunakan dalam konteks akademik. Untuk menguasai kosa kata akademik, mahasiswa harus menguasai secara baik GWL.

Materi inti berbicara merujuk pada berbicara tingkat awal. Berbicara tingkat awal ditandai dengan penguasaan kosa kata yang masih terbatas, grammar yang masih sering salah, dan tema-tema yang harus dipersiapkan sebelumnya. Berbicara tahap awal digunakan untuk memenuhi kebutuhan dalam lingkup terbatas dan interaksi dengan penutur lain yang juga masih secara terbatas. Tema yang digunakan dalam berbicara tahap awal antara lain: memperkenalkan diri sendiri, melakukan ajakan atau permohonan, penolakan, bercerita mengenai biodata, pekerjaan, aktifitas sehari-hari dan 
menjelaskan suatu tema dalam setting tertentu. Interaksi dan tanya jawab memungkinkan dilakukan tetapi dalam skala yang masih terbatas. Korpora dalam pembicaraan banyak ditandai dengan kesalahan grammar, kosa kata dan pengucapan yang kurang tepat.

\section{Tahap Rancangan dan Pengembangan}

Sebelum diperoleh silabus versi final, prototipe silabus dikaji lebih dulu oleh tiga orang ahli yang tergabung dalam tim kolaborasi. Silabus yang dikembangkan ialah Silabus versi Cambridge University (2013). Silabus terdiri dari dua bagian: (1) penjelasan mengenai aims dan objectives, dan (2) penjelasan mengenai objectives, learning outcomes, dan indicative contents. Hasil tahap rancangan disajikan pada Tabel 1, Tabel 2, dan Tabel 3.

Untuk mencapai tujuan tersebut, materi ajar dikelompokkan ke dalam lima kompetensi, yaitu: (1) Kosa kata umum yang disebut dengan kota kata 1.000 dan 2.000 atau General Word List (GWL), (2) Grammar dasar, (3) Kosa kata akademik, (4) Membaca pemahaman literal dan inferential, dan (5) Berbicara tahap awal untuk komunikasi sehari-hari.

Tabel 1. Aim dan Objectives Silabus EAP

\begin{tabular}{|l|l|}
\hline \multicolumn{1}{|c|}{ Aim } & \multicolumn{1}{c|}{ Objectives } \\
\hline $\begin{array}{l}\text { 1. To achieve competency on basic } \\
\text { academic literacy in reading and } \\
\text { speaking skills }\end{array}$ & 1. $\begin{array}{l}\text { To increase basic knowledge on } \\
\text { vocabulary }\end{array}$ \\
& $\begin{array}{l}\text { 2. To increase mastery on basic grammar } \\
\text { 3. To develop academic vocabulary } \\
\text { through reading and basic speaking }\end{array}$ \\
& $\begin{array}{l}\text { 4. To develop reading skills in literal and } \\
\text { inferential comprehension } \\
\text { To develop basic speaking skills for } \\
\text { daily communication }\end{array}$ \\
\hline
\end{tabular}

Adapted from Solikhah (2014) dan Solikhah et.al (2014a).

Rumusan materi ajar dan learning outcomes kemudian dikembangkan menjadi silabus untuk pedoman tatap muka selama satu semester. Untuk semester berikutnya materi dikembangkan berbasis pada critical reading dan lanjutan grammar dan berbicara yang lebih tinggi levelnya. Materi kosa kata GWL dan kosa kata akademik tetap digunakan. 
Tabel 2. Operasional Silabus EAP Berbasis Learning Outcomes A

\begin{tabular}{|c|c|c|c|}
\hline No & Contents & Learning Outcomes & Indicative Contents \\
\hline 1 & $\begin{array}{l}\text { Vocabulary } \\
1,000 \text { and basic } \\
\text { speaking }\end{array}$ & $\begin{array}{l}\text { 1. Demonstrating literal } \\
\text { comprehension } \\
\text { 2. Demonstrating } \\
\text { introduction orally }\end{array}$ & $\begin{array}{l}\text { 1. Literal comprehension } \\
\text { 2. GWL } 1.000 \\
\text { 3. Parts of Speeches } \\
\text { 4. Introducing One-Self }\end{array}$ \\
\hline 2 & $\begin{array}{l}\text { Vocabulary } \\
1,000 \text { and basic } \\
\text { speaking }\end{array}$ & $\begin{array}{l}\text { 1. Demonstrating } \\
\text { ability to find main } \\
\text { ideas in a text } \\
\text { 2. Explaining orally }\end{array}$ & $\begin{array}{l}\text { 1. Reading for main ideas } \\
\text { 2. GWL } 1,000 \\
\text { 3. To be, tenses, agreements, } \\
\text { 4. Telling and explaining orally }\end{array}$ \\
\hline 3 & $\begin{array}{l}\text { Vocabulary } \\
2,000 \text { and } \\
\text { speaking for } \\
\text { discussion }\end{array}$ & $\begin{array}{l}\text { 1. Applying skimming } \\
\text { and scanning from } \\
\text { passages } \\
\text { 2. Telling facts for } \\
\text { discussion orally }\end{array}$ & $\begin{array}{l}\text { 1. Skimming and scanning for } \\
\text { details } \\
\text { 2. GWL 2,000 } \\
\text { 3. Sentences, gerunds } \\
\text { 4. Telling jobs and education }\end{array}$ \\
\hline 4 & $\begin{array}{l}\text { Vocabulary } \\
2,000 \text { and } \\
\text { Speaking } \\
\text { performance }\end{array}$ & $\begin{array}{l}\text { 1. Demonstrating } \\
\text { context to develop } \\
\text { vocabulary } \\
\text { 2. Performance for } \\
\text { formal presentation }\end{array}$ & $\begin{array}{l}\text { 1. Using context for vocabulary } \\
\text { 2. GWL } 2,000 \text { and academic } \\
\text { vocabulary } \\
\text { 3. Passive voices } \\
\text { 4. Performance for formal } \\
\text { setting }\end{array}$ \\
\hline 5 & $\begin{array}{l}\text { Academic } \\
\text { Vocabulary } \\
\text { and formal } \\
\text { speaking }\end{array}$ & $\begin{array}{l}\text { 1. Demonstrating } \\
\text { ability to find main } \\
\text { ideas in a text } \\
\text { 2. Explaining orally }\end{array}$ & $\begin{array}{l}\text { 1. Inferential Reading } \\
\text { 2. GWL 2,000 and academic } \\
\text { vocabulary } \\
\text { 3. Clauses } \\
\text { 4. Formal speaking in the class }\end{array}$ \\
\hline 6 & $\begin{array}{l}\text { Vocabulary } \\
2,000 \text { and } \\
\text { speaking for } \\
\text { discussion }\end{array}$ & $\begin{array}{l}\text { 1. Applying inferences } \\
\text { from TOEFL } \\
\text { passages } \\
\text { 2. Telling reason for } \\
\text { future ideas }\end{array}$ & $\begin{array}{l}\text { 1. Making inferences } \\
\text { 2. GWL 2,000 \& academic } \\
\text { vocabulary } \\
\text { 3. Compound complex } \\
\text { sentences } \\
\text { 4. Telling future ideas }\end{array}$ \\
\hline 7 & $\begin{array}{l}\text { Vocabulary } \\
2,000 \text { and } \\
\text { Speaking } \\
\text { performance }\end{array}$ & $\begin{array}{l}\text { 1. Identifying meaning } \\
\text { from TOEFL } \\
\text { passages } \\
\text { 2. Performance for } \\
\text { formal presentation }\end{array}$ & $\begin{array}{l}\text { 1. Referring to the passages and } \\
\text { critical comprehension } \\
\text { 2. GWL 2,000 and academic } \\
\text { vocabulary } \\
\text { 3. Miscellaneous grammar } \\
\text { topics } \\
\text { 4. Performance for formal } \\
\text { setting }\end{array}$ \\
\hline
\end{tabular}

Adapted from Solikhah (2014) dan Solikhah et.al (2014a). 
Materi ajar dalam silabus di atas ada 7 jenis yang menunjukkan jumlah bab atau jumlah membahasan. Satu pembahasan seyogyanya diajarkan untuk dua tatap muka sehingga total seluruh pertemuan ialah 14 kali. Jika dibuat ujian dua kali, yaitu midterm dan final test, akan diperoleh 16 tatap muka. Aktifitas membaca pemahaman menjadi materi pokok diikuti dengan latihan kosa kata, grammar dan latihan berbicara. Contoh, pembahasan pertama berisi: literal comprehension, General Word List 1,000, parts of speeches, dan introducing one-self. Artinya, pertemuan pertama mengajarkan membaca literal, dilanjutkan dengan pengembangan kosa kata 1.000, grammar dengan topik parts of speeches, dan berbicara dengan topik memperkenalkan diri sendiri. Untuk semester kedua, silabus ini tetap bisa digunakan dengan level pre-intermediate. Materi dikembangkan dari aspek sumber bahan dan bobot bahan ajarnya.

Silabus ini dirancang untuk dua semester, ganjil untuk level elementary dan genap untuk level pre-intermediate. Sesuai hasil wawancara, analisis jawaban angket dan pengamatan lapangan, dipastikan bahwa level pemahaman mahasiswa berada pada tahap elementary. Materi inti EAP Berbasis Learning Outcomes sudah mencakup level intermediate karena kosa kata akademik dan membaca kritis sudah dipersyaratkan sebagai materi inti. Untuk itu, silabus dipecah ke dalam dua bagian. Silabus yang disusun ini digunakan untuk level elementary. Adapun silabus untuk level preintermediate disajikan pada tabel 3.

Tabel 3. Operasional Silabus EAP Berbasis Learning Outcomes B

\begin{tabular}{|c|c|c|c|}
\hline No & Contents & Learning Outcomes & Indicative Contents \\
\hline 1 & $\begin{array}{l}\text { Vocabulary } \\
2,000, \\
\text { academic } \\
\text { vocabulary and } \\
\text { speaking } \\
\text { performance }\end{array}$ & $\begin{array}{l}\text { 1. Demonstrating } \\
\text { inferential } \\
\text { comprehension } \\
\text { 2. Demonstrating } \\
\text { formal speeches }\end{array}$ & $\begin{array}{l}\text { 1. Inferential comprehension } \\
\text { 2. GWL 2,000 \& academic } \\
\text { vocabulary } \\
\text { 3. Complex sentences } \\
\text { 4. Delivery speeches }\end{array}$ \\
\hline 2 & $\begin{array}{l}\text { Vocabulary } \\
2,000, \\
\text { academic } \\
\text { vocabulary and } \\
\text { public } \\
\text { speaking }\end{array}$ & $\begin{array}{l}\text { 1. Demonstrating } \\
\text { ability to find } \\
\text { various types of } \\
\text { inferential reading } \\
\text { 2. Managing a forum }\end{array}$ & $\begin{array}{l}\text { 1. Inferential comprehension } \\
\text { 2. GWL 2,000 and academic } \\
\text { vocabulary } \\
\text { 3. Grammar for TOEFL } \\
\text { 4. Performance for Master of } \\
\text { ceremony }\end{array}$ \\
\hline 3 & $\begin{array}{l}\text { Vocabulary } \\
2,000, \\
\text { academic } \\
\text { vocabulary and } \\
\text { speaking for } \\
\text { discussion }\end{array}$ & $\begin{array}{l}\text { 1. Applying critical } \\
\text { reading from } \\
\text { passages } \\
\text { 2. Telling facts for } \\
\text { discussion orally }\end{array}$ & $\begin{array}{l}\text { 1. Critical comprehension } \\
\text { 2. GWL 2,000 and academic } \\
\text { vocabulary } \\
\text { 3. Exercises of grammar from } \\
\text { TOEFL texts } \\
\text { 4. Round table and moderator }\end{array}$ \\
\hline
\end{tabular}

Adapted from Solikhah (2014) dan Solikhah et.al (2014a). 
Tabel 3. Operasional Silabus EAP Berbasis Learning Outcomes B

\begin{tabular}{|c|c|c|c|}
\hline No & Contents & Learning Outcomes & Indicative Contents \\
\hline 4 & $\begin{array}{l}\text { Vocabulary } \\
2,000, \\
\text { academic } \\
\text { vocabulary and } \\
\text { Speaking } \\
\text { performance }\end{array}$ & $\begin{array}{l}\text { 1. Writing a summary } \\
\text { of a text } \\
\text { 2. Performance for } \\
\text { formal presentation }\end{array}$ & $\begin{array}{l}\text { 1. Reading for analysis } \\
\text { 2. GWL 2,000 and academic } \\
\text { vocabulary } \\
\text { 3. Grammar from international } \\
\text { tests } \\
\text { 4. Seminar }\end{array}$ \\
\hline 5 & $\begin{array}{l}\text { Academic } \\
\text { Vocabulary } \\
\text { and formal } \\
\text { speaking }\end{array}$ & $\begin{array}{l}\text { 1. Writing a paraphrase } \\
\text { from a text } \\
\text { 2. Explaining orally }\end{array}$ & $\begin{array}{l}\text { 1. Reading for analysis } \\
\text { 2. GWL 2,000 and academic } \\
\text { vocabulary } \\
\text { 3. Grammar exercise from } \\
\text { various tests } \\
\text { 4. Formal and informal } \\
\text { speeches }\end{array}$ \\
\hline 6 & $\begin{array}{l}\text { Academic } \\
\text { Vocabulary } \\
\text { and formal } \\
\text { academic } \\
\text { presentation }\end{array}$ & $\begin{array}{l}\text { 1. Giving written } \\
\text { comments for } \\
\text { different two texts } \\
\text { 2. Oral Comments for } \\
\text { academic } \\
\text { presentation }\end{array}$ & $\begin{array}{l}\text { 1. Reading for synthesis } \\
\text { 2. GWL 2,000 \& academic } \\
\text { vocabulary } \\
\text { 3. Grammar for academic texts } \\
\text { 4. Presenting topics for } \\
\text { academic contents }\end{array}$ \\
\hline 7 & $\begin{array}{l}\text { Academic } \\
\text { Vocabulary } \\
\text { and academic } \\
\text { Speaking } \\
\text { performance }\end{array}$ & $\begin{array}{l}\text { 1. Clarification and } \\
\text { explaining for } \\
\text { written academic } \\
\text { settings } \\
\text { 2. Performance for } \\
\text { formal presentation }\end{array}$ & $\begin{array}{l}\text { 1. Referring for synthesis } \\
\text { 2. GWL 2,000 and academic } \\
\text { vocabulary } \\
\text { 3. Miscellaneous grammar } \\
\text { topics } \\
\text { 4. Performance for academic } \\
\text { settings }\end{array}$ \\
\hline
\end{tabular}

Adapted from Solikhah (2014) dan Solikhah et.al (2014a).

\section{BAHASAN}

\section{Hasil Pendefinisian}

Kondisi pembelajaran MKDU Bahasa Inggris di IAIN Surakarta belum memuaskan. Indikator yang menunjukkan kurang memuaskan ada tiga: (1) Tujuan pembelajaran belum dirumuskan dengan jelas, Silabus sebagai pedoman penyusunan program pembelajaran dan materi ajar belum tersedia, dan manajemen pengelolaan MKDU Bahasa Inggris bersifat sebagai syarat lulus.

Temuan ini mengkonfirmasi hasil penelitian Solikhah (2014) yang mengkaji buku teks berbasis akademik di PTN se-Jawa Tengah dan DIY. Dilihat dari materi dan manajemennya, kondisi MKDU Bahasa Inggris di IAIN Surakarta bahkan lebih kurang mantap. Di IAIN Surakarta, silabus, buku teks, dan evaluasi belum terprogram dengan baik. Di PTN Jawa Tengah dan DIY silabus, buku teks dan sistem evaluasi MKDU 
Bahasa Inggris sudah terlaksana dengan baik walaupun belum memenuhi standar EAP Internasional dan belum berbasis kompetensi.

Temuan ini menunjukkan bahwa pelaksanaan MKDU Bahasa Inggris di IAIN Surakarta baik yang dilaksanakan di fakultas maupun di UP2B perlu diubah orientasinya. Tujuan pembelajaran diarahkan pada learning outcomes dan learning objectives. Learning outcomes diarahkan untuk mencapai literasi akademik dan learning objectives diarahkan untuk mencapai kompetensi minimal belajar bahasa Inggris. Core materials yang harus dicakup meliputi: membaca, berbicara, kosa kata 1.000-2.000, kosa kata akademik, dan grammar dasar.

Hasil analisis kebutuhan menunjukkan bahwa mahasiswa masih berada dalam level awal belajar bahasa sehingga menyebutkan kosa kata, grammar, dan berbicara tahap awal sebagai daftar kebutuhan pertama. Selain itu, materi MKDU Bahasa Inggris belum sejalan dengan tujuan belajar. Akibatnya, bahan ajar inti yang harus diajarkan tidak terstandar. Kualitas bahan ajar yang disusun sesuai dengan analisis kebutuhan dan penyajian materi ajar menjadi persoalan yang menyebabkan MKDU Bahasa Inggris kurang berbobot. Keadaan ini dipersulit dengan sistem rewards yang diberikan terhadap dosen MKDU Bahasa Inggris yang kurang memihak pada dosen. Selain dosen kelebihan jam mengajar di Prodi asal, dosen mengajar MKDU Bahasa Inggris sebagai pengabdian. Dampaknya, perhatian dosen untuk meningkatkan kualitas pembelajaran dan perjuangan untuk meingkatkan kompetensi mahasiswa tidak bergairah. Temuan ini menunjukkan bahwa MKDU Bahasa Inggris di IAIN Surakarta harus diubah secara fundamental. Perubahan dimulai dari perumusan learning outcomes, learning objectives, materi ajar, metodologi, dan evaluasi sebagaimana ditegaskan oleh hasil penelitian ini.

Kerangka silabus EAP Berbasis Learning Outcomes menunjukkan bahwa literasi akademik dan kompetensi minimal bahasa Inggris menjadi perhatian utama. Materi inti yang diajarkan meliputi: membaca literal dan inferensial, kosa kata 1.0002.000, kosa kata akademik, grammar dasar, dan berbicara tahap awal. Temuan ini menunjukkan bahwa program MKDU Bahasa Inggris di IAIN Surakarta harus diubah secara mendasar. Perubahan dimulai dengan penyusunan silabus dan bahan ajar inti yang terstandar. Silabus hasil penelitian ini digunakan untuk dua semester; pemisahan materi dilakukan pada empat aspek: membaca kritis, kosa kata akademik, grammar akademik, dan berbicara dalam setting formal dan topik terbaru digunakan sebagai materi inti pada semester kedua untuk level pre-intermediate.

\section{Hasil Rancangan dan Pengembangan}

Silabus EAP Berbasis Learning Outcomes hasil penelitian ini dikembangkan dengan mengadaptasi silabus EAP dari Solikhah (2014) dan Solikhah dkk (2014a). Model silabus mengikuti Delta Cambridge Syllabus (2013) yang digunakan di Cambridge University. Isi silabus terdiri dari dua bagian, yaitu (1) rumusan aims dan learning objectives, dan (2) rumusan isi materi, learning outcomes, dan indicative contents. Penelitian ini memodifikasi Delta Cambridge Syllabus tersebut dan diberi nama Silabus Berbasis Learning Outcomes.

Temuan penelitian ini menunjukkan bahwa rumusan silabus berdasarkan aims dan objectives, kemudian uraian menurut isi, learning outcomes dan indicative contents 
terbukti sangat praktis dan mudah dipahami. Indikator capaian menjadi mudah dideskripsikan dan materi ajar mudah dipilih. Silabus jenis ini sebenarnya ialah silabus berbasis kompetensi. Dalam kajian yang lebih cermat, kompetensi ialah bagian dari learning outcomes. Learning outcomes ialah kumpulan kompetensi yang harus dicapai setelah keseluruhan bahan ajar dikuasai. Terdapat tiga tingkatan kompetensi menurut konsep ini, yaitu: learning outcomes, aims atau goals, dan objectives. Learning outcomes bersifat lebih luas berisi kompetensi akhir yang harus dicapai setelah program selesai. Aims atau goals ialah tujuan umum pembelajaran setelah satu perkuliahan diajarkan. Objectives ialah tujuan khusus yang ditentukan sesuai dengan tema atau topik yang diajarkan. Satu aims bisa berisi beberapa objectives. Gabungan antara aims dan objectives membentuk learning outcomes. Deskripsi bagaimana tujuan dan tahapan capaian belajar dilaksanakan, dirumuskan dalam kolom aims dan learning objectives. Selanjutnya, untuk menunjukkan kesesuaian antara learning outcomes dengan materi dan rincian isi materi dijabarkan dalam contents dan learning outcomes.

Hasil penelitian ini menggarisbawahi beberapa dua hal. Pertama, MKDU Bahasa Inggris yang sebelumnya bersifat general English diubah menjadi pembelajaran berbasis kompetensi dan tujuan pembelajarannya disebut dengan EAP Berbasis Learning Outcomes. Tujuan belajar dirumuskan ke dalam dua hal, untuk mencapai literasi akademik dan untuk mencapai kompetensi minimal bahasa Inggris. Kedua, materi inti (core materials) dalam EAP Berbasis Learning Outcomes dalam penelitian ini meliputi: keterampilan berbahasa, yaitu membaca dan berbicara dan penguasaan aspek kebahasaan: kosa kata dan grammar. Secara lebih spesifik, membaca yang ditargetkan ialah membaca literal dan membaca inferensial. Berbicara yang dimaksud ialah berbicara tahap reproduksi untuk keperluan sehari-hari, misalnya perkenalan, bercerita mengenai riwayat hidup, pekerjaan. Topik formal seperti presentasi, debat, pidato belum dijadikan capaian kompetensi. Untuk mendukung keterampilan membaca dan berbicara tersebut, diberikan kosa kata 1.000-2.000 sebagai kosa kata minimal penguasaan bahasa Inggris dan grammar dasar.

Penelitian ini juga menemukan bahwa keterampilan menyimak dan menulis tidak dimasukkan dalam menu kebutuhan belajar oleh mahasiswa. Jawaban yang diperoleh dari hasil wawancara menunjukkan bahwa keterampilan menyimak dianggap relatif merepotkan karena dosen berbendapat mengajar menyimak kurang leluasan jika tidak menggunakan laboratorium bahasa. Persoalan muncul karena belajar di lab bahasa memerlukan persiapan yang lebih rumit. Keterampilan menulis dianggap sulit dan belum diperlukan untuk pembelajar tingkat awal. Menulis memerlukan penguasaan kosa kata yang sudah mapan dan grammar yang juga sudah menengah. Untuk itu, silabus EAP Berbasis Learning Outcomes hasil penelitian ini sesuai dengan hasil analisis kebutuhan memang diperuntukkan mahasiswa tingkat dasar. Dalam konteks pelaksanaan EAP di IAIN Surakarta baik yang dilakukan di fakultas maupun di UP2B, hasil penelitian ini bisa dirumuskan bahwa MKDU Bahasa Inggris harus diubah menjadi EAP Berbasis Learning Outcomes. EAP Berbasis Learning Outcomes dibagi menjadi dua bagian, Level Dasar (Elementary Level) untuk semester I dan Level Menengah (Intermediate Level) untuk semester II. Jadi, EAP Berbasis Learning Outcomes harus terdiri dari sekurang-kurangnya 4 sks. Agar pelaksanaannya berjalan 
CENDEKIA, Vol. 11, No. 2, Oktober 2017

p ISSN: 1978 2098; e ISSN: 2407 8557

Http://cendekia.pusatbahasa.or.id; Email: cendekiaoslo@gmail.com Center of Language and Culture Studies, Surakarta, Indonesia

Solikhah, Imroatus. 2017. Silabus EAP Berbasis Learning Outcomes

untuk Mahasiswa IAIN Surakarta. Cendekia (2017), 11(2): 263 278.

mudah, program EAP di IAIN Surakarta hendaknya dilaksanakan dalam satu manajemen yaitu dikelola oleh UP2B IAIN Surakarta.

\section{SIMPULAN}

1) Kondisi pembelajaran MKDU Bahasa Inggris di IAIN Surakarta tergolong belum standar. MKDU Bahasa Inggris berbobot 2-4 sks, wajib diikuti setiap mahasiswa pada semester I dan semester II dan satu kelas diisi 40 mahasiswa. Tidak terdapat silabus dan kurikulum sebagai pedoman mengajar dosen. Institut mengarahkan MKDU Bahasa Inggris bertujuan meningkatkan skor TOEFL mahasiswa tetapi isi bahan ialah basic grammar dan membaca pemahaman atau general English. Pendekatan yang digunakan untuk mengajar MKDU Bahasa Inggris ialah mengarah pada grammar translation methods, karena interaksi lebih banyak menggunakan bahasa Indonesia, materi ajar lebih difokuskan pada grammar dan menjawab pertanyaan membaca.

Analisis kebutuhan menunjukkan tujuan MKDU menurut institut ialah menguasai bahasa Inggris dan meningkatkan skor TOEFL. Dipandu dengan tujuan tersebut daftar kebutuhan mahasiswa mencakup: kosa kata, grammar, berbicra bahasa Inggris tahap awal untuk komunikasi lisan, membaca teks bahasa Inggris, menyimak, dan menulis pesan pendek. Tujuan tersebut dipadukan dengan hasil jawaban wawancara dan angket dan dirumuskan kembali menjadi: (1) Tujuan umum EAP ialah untuk menguasai bahasa Inggris untuk akademik dan tujuan khususnya ialah untuk menguasai kompetensi dasar membaca dan berbicara. (2) Materi inti MKDU Bahasa Inggris ialah membaca, berbicara, kosa kata 1.000-2.000, kosa kata akademik, dan grammar dasar. Membaca tingkat dasar mencakup membaca literal dan inferensial. Adapun berbicara bertujuan untuk komunikasi sehari-hari dalam lingkup terbatas. Hasil analisis kebutuhan tersebut digunakan sebagai kerangka inti silabus EAP Berbasis Learning Outcomes.

2) Silabus yang dikembangkan ialah Silabus versi Cambridge University (2013). Silabus terdiri dari dua bagian: (1) penjelasan mengenai aims dan objectives, dan (2) penjelasan mengenai objectives, learning outcomes, dan indicative contents. Materi ajar dalam silabus ada 7 jenis yang menunjukkan jumlah bab atau jumlah membahasan. Satu pembahasan bisa diajarkan lebih dari satu tatap muka sehingga total seluruh pertemuan bisa berkisar 14 kali. Aktifitas membaca pemahaman menjadi materi pokok diikuti dengan latihan kosa kata, grammar dan latihan berbicara. Contoh, pembahasan pertama berisi: literal comprehension, General Word List 1,000, parts of speeches, dan introducing one-self. Artinya, pertemuan pertama mengajarkan membaca literal, dilanjutkan dengan pengembangan kosa kata 1.000, grammar dengan topik parts of speechs, dan berbicara dengan topik memperkenalkan diri sendiri. Idealnya satu pembahasan ini diajarkan selama dua tatap muka, sehingga 7 pembahasan diselesaikan dalam 14 tatap muka. Materi untuk semester kedua berbasis pada membaca kritis dan kosa kata akademik. Adapun materi grammar dan berbicara bersifat melanjutkan. 
3) Penyebarluasan hasil penelitian ini dilakukan dengan cara silabus EAP Berbasis Learning Outcomes diterapkan di UP2B IAIN Surakarta mulai pada semester berjalan.

\section{DAFTAR PUSTAKA}

Arreola, R and Lawrence. 2013. Writing Learning Objectives. Memphis: University of Tennessee.

Bjorkman, Beyza. 2011. English as a Lingua Franca in Higher Education: Implications for EAP. Iberica, 22:79-100.

Candlin, CN. 1984. Syllabus Design as a Critical Process. In Brumfit, C,J (Ed.). General English Syllabus Design, ELT Document. London: Pergamon Press.

Hyland \& Hamp-Lyons. 2006. EAP: Issues and Directions. Journal of English for Academic Purposes, 1:1-12. www.elsevier.com/locate/jeap.

Learning Management Corporation. 2013. Developing Clear Learning Outcomes and Objectives. Available at: www.thelearningmanager.com

Mukoroli, Joseph. 2011. Effective Vocabulary Teachig Strategies for the English for Academic Purposes ESL Classroom. Master's Thesis. Brattleboro, Vermont: The SIT Graduate Institute.

Munby, J. 1978. Communicative Syllabus Design. Cambridge: Cambridge University Press.

Palm Beach State College. 2013. Academic Management Manual: Outcomes Assessment Workbook. Available at: www.palmbeachstate.edu/academicservices/documents/sectionl.pdf.

Phillipson, R. 1992. Linguistic Imperialism. Oxford: Oxford University Press.

Queen Mary University of London. 2013. Good Practice Guide on Writing Aims and Learning Outcomes. Available at: www.learninginstitute.qmul.ac.uk.

Richards, Jack. 2013. Currciulum Approaches in Language Teaching: Forward, Central, and Backward Design. RELC Journal, 44(1):5-33.

Solikhah, Imroatus. 2013. English for Academic Purposes Voices: A Survey on Practices and Challenges in the State Universities of Central Java, Indonesia. International Journal of Academic Research, 5(4):121-125.

Solikhah, Imroatus. 2014. Buku Teks Bahasa Inggris Akademik Berbasis Kompetensi untuk Mahasiswa Jurusan Non-Bahasa Inggris (Penelitian dan Pengembangan di Perguruan Tinggi Negeri di Jawa Tengah dan DIY). Disertasi Doktor. Surakarta: FKIP Universitas Sebelas Maret.

Solikhah, Imroatus, et. al. 2014a. A Competency-Based Textbook for the Learners of Non-English Program (Research and Development in State Universities in Central Java and Yogjakarta) Indonesia. International Journal of Language and Literature, 5(3):1-9.

Solikhah, Imroatus, et. al. 2014b. English for Academic Purposes: a CompetencyBased Textbook for EFL Learners. Yogyakarta: Penerbit Imperium.

Strevens, P. 1988. ESP after Twenty Years: A Re-appraisal. In M. Tickoo (Ed.), ESP: State of the Art (pp. 1-13). Singapore: SEAMEO Regional Language Centre. 
CENDEKIA, Vol. 11, No. 2, Oktober 2017

p ISSN: 1978 2098; e ISSN: 2407 8557

Http://cendekia.pusatbahasa.or.id; Email: cendekiaoslo@gmail.com Center of Language and Culture Studies, Surakarta, Indonesia

Solikhah, Imroatus. 2017. Silabus EAP Berbasis Learning Outcomes untuk Mahasiswa IAIN Surakarta. Cendekia (2017), 11(2): 263 278.

University of Cambridge. 2011. Delta Syllabus Specifications. Cambridge: University of Cambridge ESOL Examinations. Available at: www.CambridgeESOL.org.

West, M. 1953. A General Service List of English Words. London: Longman. Retrieved July 10, 2012 from http:/jbauman.com/gsl.html

Willis, J. 1995. A Recursive, Reflective Instructional Design Model Based on Constructivist-Interpretative Theory. Educational Technology, 1995(6): $5-23$.

Wilson, Kate. 2009. Reading in the Margins: EAP Reading Pedagogies and Their Critical, Postcritical Potential. Ph.D's Dissertation. Sydney: University of Technology.

Yurekli, Aynur. 2012. An Analysis of Curriculum Renewal in EAP Context. International Journal of Instruction, 5(1):49-68. 